\section{$\underset{\substack{\text { hommes } \\ \text { \& migrations }}}{ }$}

\section{Hommes \& migrations}

Revue française de référence sur les dynamiques

migratoires

1329 | 2020

Migrations et création littéraire

\title{
Frédéric Hermel, Zidane
}

Flammarion, Paris, 2019, 288 pages, 19,90€.

\section{Mouloud Mimoun}

\section{(2) OpenEdition \\ 12 Journals}

\section{Édition électronique}

URL : https://journals.openedition.org/hommesmigrations/11277

DOI : 10.4000/hommesmigrations. 11277

ISSN : 2262-3353

\section{Éditeur}

Musée national de l'histoire de l'immigration

\section{Édition imprimée}

Date de publication : 1 avril 2020

Pagination : 195

ISBN : ISBN 978-2-919040-50-6

ISSN : 1142-852X

\section{Référence électronique}

Mouloud Mimoun, « Frédéric Hermel, Zidane », Hommes \& migrations [En ligne], 1329 | 2020, mis en ligne le 01 avril 2020, consulté le 04 janvier 2023. URL : http://journals.openedition.org/

hommesmigrations/11277; DOI : https://doi.org/10.4000/hommesmigrations.11277 


\section{Livres}

\section{Zidane}

Frédéric Hermel, Paris, Flammarion, 2019, 288 pages, 19,90 euros.

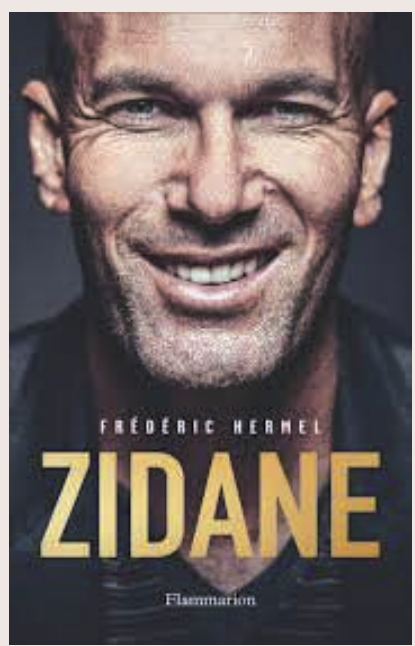

Nombre d'ouvrages consacrés à l'icône Zinédine Zidane ont chanté les louanges du footballeur à la technique hors pair et à la carrière unique.

Mais aucun n'a jamais été aussi complet et pertinent que ce Zidane paru chez Flammarion récemment, sous la plume de Frédéric Hermel, correspondant du journal L'Équipe à Madrid et journaliste également sur Radio Monte Carlo. Une forte amitié, pour ne pas dire complicité, a rapproché très vite le natif du Nord de la France et l'enfant de la Castellane, cette cité de Marseille où Zizou a vu le jour entouré des siens, Smaïl et Malika, les parents nés en Kabylie, et les trois frères et la sœur qui l'ont couvé d'amour et d'affection, lui, le petit dernier de la fratrie qui a vu le jour le 23 juin 1972.

De ce père ouvrier et de cette mère au foyer, Yazid - deuxième prénom réservé aux intimes - a hérité d'une éducation résumée par les recommandations de Smaïl qui tiennent en trois mots prononcés le jour où, à 15 ans, il quitte le cocon familial pour rejoindre le centre de formation de l'AS Cannes: "Travail, sérieux et respect.»

Frédéric Hermel conte avec chaleur et précision les différentes étapes de la jeunesse de "Yaz», marquée par la rencontre amoureuse avec Véronique et l'amitié indéfectible qui le lie à David Bettoni, aujourd'hui son adjoint au Real Madrid. Zidane, sans doute le français le plus connu dans le monde, est un mythe, une icône mondiale, un modèle. Extraordinaire footballeur, aujourd'hui entraîneur adulé au palmarès unique avec trois ligues des champions (2016, 2017, 2018) consécutives avec le Real Madrid, sa destinée est hors norme, jalonnée de succès incroyables et de coups de sang mémorables. Ainsi de son rapport à la politique qui le fera sortir de sa réserve naturelle à deux reprises: en 2002, Bruno Gollnish, un des leaders du Front national, le catalogue de fils de harkis. La réponse est cinglante: «Eh bien mon père n'a jamais combattu contre son pays, c'est clair? Mon père est un Algérien fier de l'être, et moi je suis fier que mon père soit un Algérien!»

D'ailleurs Zidane, qui ne parle pourtant jamais de politique, appellera pour le second tour des présidentielles de 2002 à ne pas voter pour Jean-Marie Le Pen. Il récidivera en 2017 à propos de sa fille Marine.

Le journaliste écrivain Frédéric Hermel passe en revue toutes les personnes qui ont marqué son existence et raconte avec force détails sa vie au quotidien, ses motivations actuelles, écrivant ceci: "J'affirme (...) que Zidane deviendra encore plus grand entraîneur qu'il n'a été joueur.»

Ce que confirme Msaidié, l'entraîneur en second au Real Madrid: "Zidane a ce truc essentiel dans notre métier, c'est qu'il synthétise très vite. Les idées sont limpides, les concepts bien choisis et très clairs. Il sait où il veut aller, comment il veut y aller et possède en lui cette capacité de le transmettre. C'est simple à comprendre pour les joueurs et pour nous aussi qui travaillons auprès de lui. Avec Zizou, il n'y a pas de palabres et, en même temps, il pose beaucoup de questions, demande conseil, laisse aux autres la possibilité de s'exprimer et permet la confrontation des idées. » Cette réflexion pertinente sur l'entraîneur recoupe parfaitement tout ce que cet ouvrage raconte de l'être intime qui se dissimule derrière la star.

\section{Mouloud Mimoun}

